\title{
The role of transaction costs and risk aversion when selecting between one and two regimes for portfolio models
}

Article

Accepted Version

Platanakis, E., Sakkas, A. and Sutcliffe, C. (2019) The role of transaction costs and risk aversion when selecting between one and two regimes for portfolio models. Applied Economics Letters, 26 (6). pp. 516-521. ISSN 1466-4291 doi:

https://doi.org/10.1080/13504851.2018.1486984 Available at https://centaur.reading.ac.uk/77114/

It is advisable to refer to the publisher's version if you intend to cite from the work. See Guidance on citing.

To link to this article DOI: http://dx.doi.org/10.1080/13504851.2018.1486984

Publisher: Taylor \& Francis

All outputs in CentAUR are protected by Intellectual Property Rights law, including copyright law. Copyright and IPR is retained by the creators or other copyright holders. Terms and conditions for use of this material are defined in the End User Agreement.

www.reading.ac.uk/centaur 
Central Archive at the University of Reading

Reading's research outputs online 


\title{
The Role of Transaction Costs and Risk Aversion When Selecting Between One and Two Regimes for Portfolio Models
}

\author{
Emmanouil Platanakis ${ }^{\#}$, Athanasios Sakkas ${ }^{+}$and Charles Sutcliffe*
}

$1^{\text {st }}$ April 2018

\# School of Management, University of Bath, Claverton Down, Bath, BA2 7AY, UK, email: E.Platanakis@bath.ac.uk Tel: +44(0) 1274235311

$+\quad$ Southampton Business School, University of Southampton, Highfield, Southampton SO17 1BJ, UK, email: A.Sakkas@soton.ac.uk Tel: +44(0) 2380593551

* The ICMA Centre, Henley Business School, University of Reading, PO Box 242, Reading RG6 6BA, UK, email: c.m.s.sutcliffe@rdg.ac.uk Tel +44(0) 118378 6117, Fax +44(0) 118 9314741 (corresponding author) ORCID 0000-0003-0187-487X

We wish to thank Chris Brooks and loannis Oikonomou (Reading), and Xiaoxia Ye (Bradford) for their comments on an earlier draft. 


\title{
The Role of Transaction Costs and Risk Aversion When Selecting Between One and Two Regimes for Portfolio Models
}

\begin{abstract}
Estimation of the inputs is the main problem when applying portfolio analysis, and Markov regime switching models have been shown to improve these estimates. We investigate whether the use of two regime models remains superior across a range of values of risk aversion and transaction costs, in the presence of skewness and kurtosis and no short sales. Our results for US data suggest that, due to differences in their risk preferences and transactions costs, most retail investors may prefer to use one regime models, while investment banks may prefer to use two regime models.
\end{abstract}

Key words: Portfolio theory; regime shifting; transaction costs; risk aversion; constant relative risk aversion

JEL code: G11

\section{Introduction}

Estimation of the inputs is the major problem when applying portfolio theory. The means, variances and correlations of asset returns are usually estimated by their historical values, or their transformations. But the performance of portfolio models with inputs estimated in this way has been disappointing (Levy and Simaan, 2016; Maillet, et al., 2015). The new approach of Markov regime switching models recognises that asset returns are not generated by a single economic regime, and a different set of parameters needs to be estimated for each economic regime (Bae, et al., 2014). Investors must choose between using one and multi-regime models when estimating the portfolio input parameters. To help investors make this choice, we compare the out-of-sample performance of portfolios formed using both one and two regimes.

Three papers have compared the out-of-sample performance of one and two or more regimes when short sales are banned (Angelidis \& Tessaromatis, 2014; Guidolin \& Timmermann, 2007; and Guidolin \& Ria, 2011). Asset returns are usually skewed and display kurtosis, but only Guidolin \& Timmermann (2007) have formed portfolios by maximising CRRA utility, which 
allows for skewness and kurtosis. These hree previous studies find two regimes are superior to one regime, but do not allow for a range of values for transaction costs or risk aversion.

\section{Data and Methodology}

We analyse monthly returns in US dollars from July 1961 to December 2015 on an index of US equities (value-weighted total returns for all CRSP firms incorporated in the US and listed on NYSE, AMEX and NASDAQ), and an index of US nominal bonds (US Treasury 10-year bond total returns). Following DeMiguel et al. (2009) amongst many others; our analysis is based on a 'rolling-window' approach with an estimation period of 120 months used to compute the portfolio for the next out-of-sample month.

Portfolio techniques based on only the first two statistical moments (mean-variance approaches) can suffer when asset returns do not follow a normal distribution, see Cumming et al. (2014) amongst others. We use a Taylor series expansion for the CRRA (Constant Relative Risk Aversion) utility function to incorporate higher moments in the portfolio construction process. We maximize expected CRRA utility in terms of the portfolio weights subject to no short selling constraints and normalization of portfolio weights.

We subtract transaction costs (allowing for an expected holding period of 21 months) from returns in the objective function, and when computing out-of-sample returns (IRRC Institute, 2010). We use 50 bps as the transaction costs of US equities (DeMiguel et al, 2009), and 17 bps for bonds (Edwards et al, 2007). Risk aversion varies from 2 to 10, with transaction costs of zero, one and two times their estimated level.

We estimate a two state multi-variate regime-switching model for each rolling estimation period:

$$
\begin{aligned}
& \mathbf{y}_{t}=\boldsymbol{\mu}_{1}+\boldsymbol{\varepsilon}_{t 1}, \boldsymbol{\varepsilon}_{t 1}: \operatorname{MVN}\left(0, \boldsymbol{\Sigma}_{1}\right) \text { for state } 1\left(\mathrm{~S}_{t}=1\right) \\
& \mathbf{y}_{t}=\boldsymbol{\mu}_{2}+\boldsymbol{\varepsilon}_{t 2}, \boldsymbol{\varepsilon}_{t 2}: \operatorname{MVN}\left(0, \boldsymbol{\Sigma}_{2}\right) \text { for state } 2\left(\mathrm{~S}_{t}=2\right)
\end{aligned}
$$

where $\mathbf{y}_{t}$ is a $2 \times 1$ vector of asset returns, $\boldsymbol{\mu}_{1}$ and $\boldsymbol{\mu}_{2}$ are $2 \times 1$ vectors of mean asset returns for states 1 and 2 respectively. $\boldsymbol{\varepsilon}_{t 1}$ and $\boldsymbol{\varepsilon}_{t 2}$ follow a multivariate normal distribution with zero mean and a $2 \times 2$ covariance matrix given by $\Sigma_{1}$ and $\Sigma_{2}$ for states 1 and 2 . We assume a 
Markov process with a $(2 \times 2)$ transition matrix $\boldsymbol{\Pi}$ characterised by constant probabilities $(p, q)$ defined as:

$$
\boldsymbol{\Pi}=\left[\begin{array}{cc}
\operatorname{Pr}\left(S_{t}=1, S_{t-1}=1\right) & \operatorname{Pr}\left(S_{t}=1, S_{t-1}=2\right) \\
\operatorname{Pr}\left(S_{t}=2, S_{t-1}=1\right) & \operatorname{Pr}\left(S_{t}=2, S_{t-1}=2\right)
\end{array}\right]=\left[\begin{array}{cc}
p & 1-p \\
1-q & q
\end{array}\right]
$$

At any given month $t, \mathbf{y}_{t}$ follows the distribution associated with state $S$ at month $t$. If at month $t+1 \mathbf{y}_{t+1}$ remains in the same regime, it follows the distribution of the given transition probability, $p$ or $q$; if at month $t+1 \mathbf{y}_{t+1}$ switches to the other regime, it follows the distribution of the other regime at the given transition probability, $1-p$ or $1-q$. The smoothed probability is the probability of being in state 1 or 2 conditional over the sample period. For each month, when the smoothed conditional probability over the estimation period is higher (lower) than 50\%, that month is classified as being in state 1 (state 2), Kim (1994). Following Ang and Bekaert (2004), when the realisation of the regime in the last month of each period is in state $1(S=1), \pi_{1}$ equals the transition probability $p$, i.e. $\pi_{1}=p$. When the realisation of the regime in the last month of each period is in state $2(S=2), \pi_{1}$ equals the transition probability $1-q$, i.e. $\pi_{1}=1-q$. Based on the realization of the regime in the last month of each estimation period, we compute the first four moments and the covariance matrix, as defined by Timmermann (2000), for the next out-of-sample month and use them as inputs to our portfolio model.

The regime classification measure (RCM) of Ang and Bekaert (2002) of 28.00 supports our classification of the data into two regimes. Descriptive statistics appear in Table 1 which shows the conclusions of Ang and Bekaert apply to our data. In the high volatility regime equities have lower mean returns, while in the high volatility regime bonds have higher returns.

\begin{tabular}{llcccc}
\hline No. of Regimes & Asset & Mean & Std. Dev. & Skewness & Kurtosis \\
\hline \multirow{2}{*}{ One Regime } & Equities & $10.639 \%$ & $15.374 \%$ & -0.142 & 3.156 \\
\cline { 2 - 6 } & Bonds & $6.749 \%$ & $6.062 \%$ & 0.106 & 3.357 \\
\hline $\begin{array}{l}\text { Two Regimes - } \\
\text { Low Volatility }\end{array}$ & Equities & $14.050 \%$ & $11.140 \%$ & -0.056 & 3.028 \\
\cline { 2 - 6 } & Bonds & $3.764 \%$ & $3.420 \%$ & -0.031 & 3.022 \\
\hline $\begin{array}{l}\text { Two Regimes - } \\
\text { High Volatility }\end{array}$ & Equities & $5.998 \%$ & $19.672 \%$ & -0.106 & 3.061 \\
\cline { 2 - 6 } & Bonds & $10.812 \%$ & $8.283 \%$ & -0.001 & 3.143 \\
\hline
\end{tabular}


Table 1: Descriptive Statistics for One and Two Regimes for the Entire Out-of-Sample Period Annualized Returns

\section{Results}

The eight figures show the scores for two regimes, less those for one regime, where Figures 1 to 6 use annualized returns. Figures 1 and 2 illustrate the difference in performance between one and two regimes, as measured by certainly equivalent returns (CERs) and Sharpe ratios respectively. Broadly similar results are obtained using the Sortino, Dowd, Sterling Calmar and Omega measures. The CER for a CRRA utility function is computed as $C E R_{t}=\left\{(1-\lambda) E\left[U_{t}\right]\right\}^{1 /(1-\lambda)}-1$ where $E[U]$ is the mean utility across our out-of-sample periods (Diris et al, 2015). Figures 1 and 2 indicate that, as risk aversion increases, the relative attractiveness of using two regimes decreases for all three levels of transaction cost, and the $\triangle$ CERs become or remain negative. Figures 3 and 4 show this is primarily due to an increase in the relative risk (difference in the standard deviations) of two regime models, rather than any change in expected returns. Cumulative wealth gives similar results to expected returns; and downside standard deviation, $\operatorname{Var}(99 \%)$, expected drawdown, and maximum drawdown give similar results to the standard deviation, see panels B and C of the Appendix.

For all values of $\lambda$ the one and two regime portfolio returns display negative skewness, which is attractive for imprudent investors, and positive kurtosis which is desirable for intemperate investors (Eeckoudt and Schlesinger, 2006). For low values of $\lambda$ Figure 5 shows that skewness is less negative for two regimes, while one regime has less negative skewness for high values of $\lambda$. In Figure 6 one regime has higher kurtosis than two regimes for all values of $\lambda$. So kurtosis increases the attractiveness of one regime portfolios for all investors, and skewness makes the use of two regimes more attractive for investors with low risk aversion, and less attractive for highly risk averse investors. The effects of skewness and kurtosis are incorporated by CERs, but not Sharpe ratios.

Diversification is measured as in equation (13) of Platanakis and Sutcliffe (2017), where full diversification scores $1 / \mathrm{N}$ and zero diversification scores unity. Stability is the average value of the sum of squares of the differences between the portfolio proportion for each asset in adjacent time periods. Figures 7 and 8 show that, irrespective of the levels of transaction costs 
and risk aversion, the two regime portfolios generate less diverse and less stable portfolios than the one regime portfolios. This means the two regime portfolios tend to concentrate the assets in either equities or bonds, frequently switching between them, leading to higher transactions costs than for one regime portfolios.

As transactions costs increase, the $\Delta C E R$ and $\triangle$ Sharpe ratio plots in Figures 1 and 2 shift down, and the relative attractiveness of using two regimes decreases. Looking at the $\triangle C E R s$ in Figure 1 , when transaction costs are zero the use of regimes is preferable for investors with risk aversion below six. In Figure 2, the corresponding number for Sharpe ratios is almost nine. When TC $=1$ the level of risk aversion below which two regimes are preferable drops to 4.5 for CERs, and 6.0 for Sharpe ratios. For both CERs and Sharpe ratios, when transaction costs are double their estimated values the use of two regimes is never preferable.

\section{Conclusions}

Regime switching models have been used to improve the estimation of the inputs required for portfolio analysis. Allowing for skewness and kurtosis and ruling out short sales, we have investigated the effects of transactions costs and risk aversion on the out-of-sample performance of regime shifting models. Previous research has concluded that two regimes are preferable to one regime. Our results do not support this two regime dominance. We find that prudent highly risk averse investors with high transaction costs may prefer to use one regime models; and impudent investors with low risk aversion and low transaction costs may prefer to use two regimes. This suggests one regime models are likely to appeal to retail investors (Dohmen, et al, 2005), and two regime models to investors such as proprietary traders in investment banks (Kelly, 2010).

\section{References}

Ang, A. and Bekaert, G. (2002) Regime Switching in Interest Rates, Journal of Business and Economic Statistics, 20(2), pp. 163-182.

Angelidis, T. and Tessaromatis, N. (2014) Global Portfolio Management Under State Dependent Multiple Risk Premia. Working paper, University of Peloponnese, 46 pages.

Cumming, D., Hass, L.H. and Schweitzer, D. (2014) Strategic Asset Allocation and the Role of Alternative Investments, European Financial Management, 20(3), pp. 521-547.

DeMiguel, V., Garlappi, L. and Uppal, R. (2009) Optimal Versus Naive Diversification: How Inefficient is the 1/N Portfolio Strategy?, Review of Financial Studies, 22(5), pp. 1915-1953.

Diris, B., Palm, F. and Schotman, P. (2015) Long-Term Strategic Asset Allocation: An Out-of-Sample Evaluation, Management Science, 61(9), pp. 2185-2202. 
Dohmen, T, Falk, A., Huffman, D., Sunde, U, Schupp, J. and Wagner, G.G. (2005) Individual Risk Attitudes: New Evidence from a Large Representative Experimentally-Validated Survey, Discussion paper, no. 1730 , IZA.

Eeckoudt, L. and Schlesinger, H. (2006) Putting Risk in its Proper Place, American Economic Review, 96(1), pp. 280-289.

Edwards, A.K., Harris, L.E. and Piwowar, M.S. (2007) Corporate Bond Market Transaction Costs and Transparency, Journal of Finance, 62(3), pp. 1421-1451.

Guidolin, M. and Ria, F. (2011) Regime Shifts in Mean-Variance Efficient Frontiers: Some International Evidence, Journal of Asset Management, 12(5), pp. 322-349.

Guidolin, M. and Timmermann, A. (2007) Asset Allocation Under Multivariate Regime Switching, Journal of Economic Dynamics and Control, 31(11), pp. 3503-3544.

IRRC Institute (2010) Investment Horizons: Do Managers Do What They Say? IRRC Institute and Mercer.

Kelly, R. (2010) Developments in Banking and Financial Law, Review of Banking and Finance Law, 30(1), pp. 2-118.

Kim, C.J. (1994) Dynamic Linear Models with Markov Switching. Journal of Econometrics, 60(1-2), pp. 122.

Levy, H. and Simaan, Y. (2016) More Possessions, More Worry, European Journal of Operational Research, 255(3), pp. 893-902.

Maillet, B., Tokpavi, S. and Vaucher, B. (2015) Global Minimum Variance Portfolio Optimization Under Some Model Risk: A Robust Regression-Based Approach, European Journal of Operational Research, 244(1), pp. 289-200.

Platanakis, E. and Sutcliffe, C. (2017) Asset-Liability Modelling and Pension Schemes: the Application of Robust Optimization to USS, European Journal of Finance, 23(4), pp. 324-352.

Timmermann, A. (2000) Moments of Markov Switching Models, Journal of Econometrics, 96(1), pp. 75111.

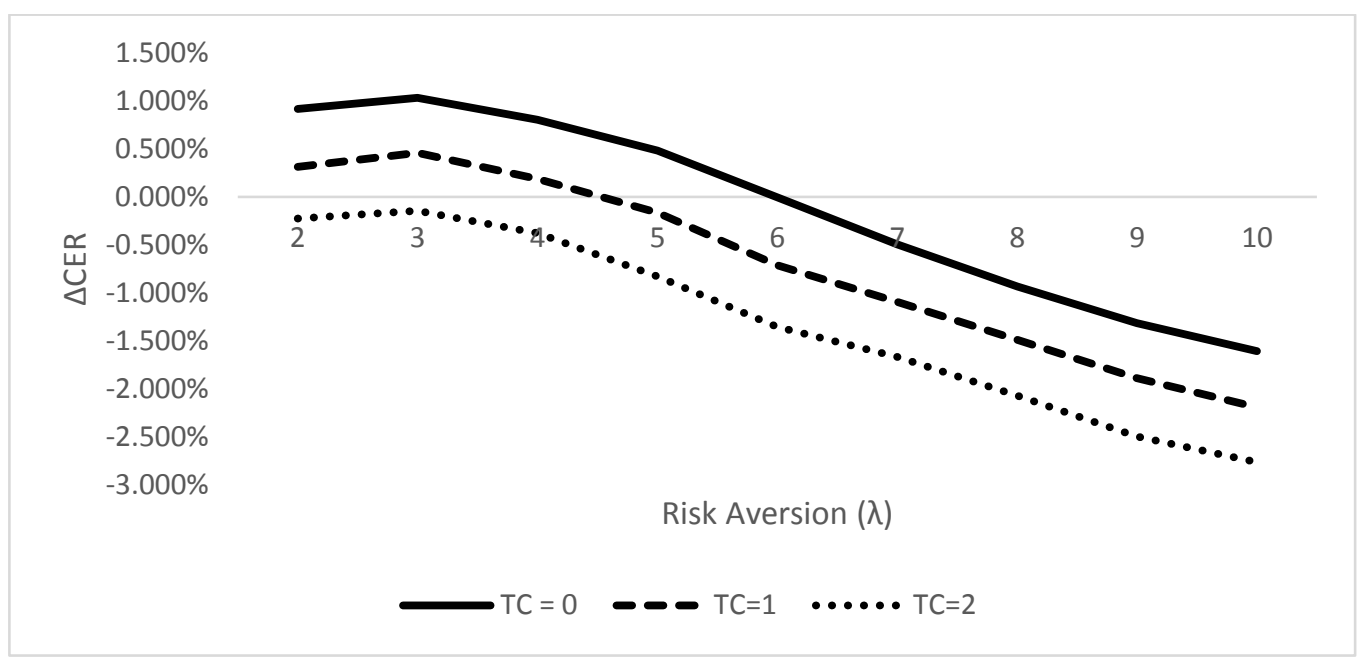

Figure 1: Two Less One Regime for Certainty Equivalent Returns 


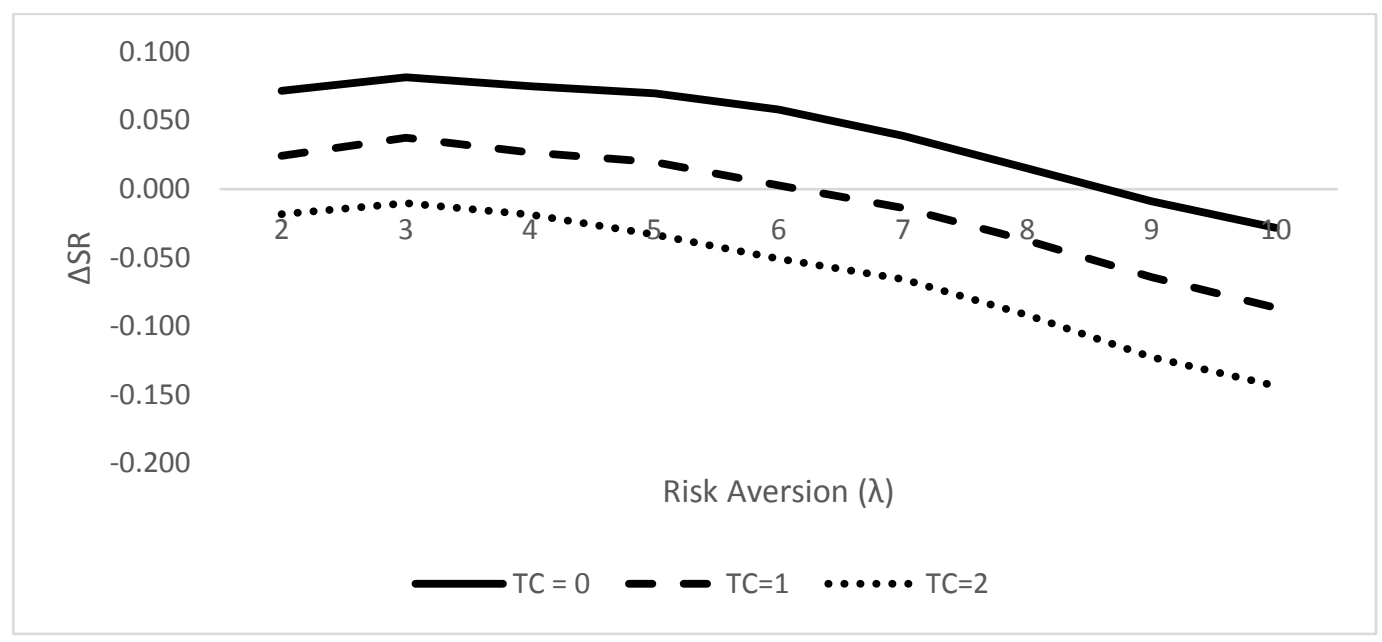

Figure 2: Two Less One Regime Sharpe Ratios

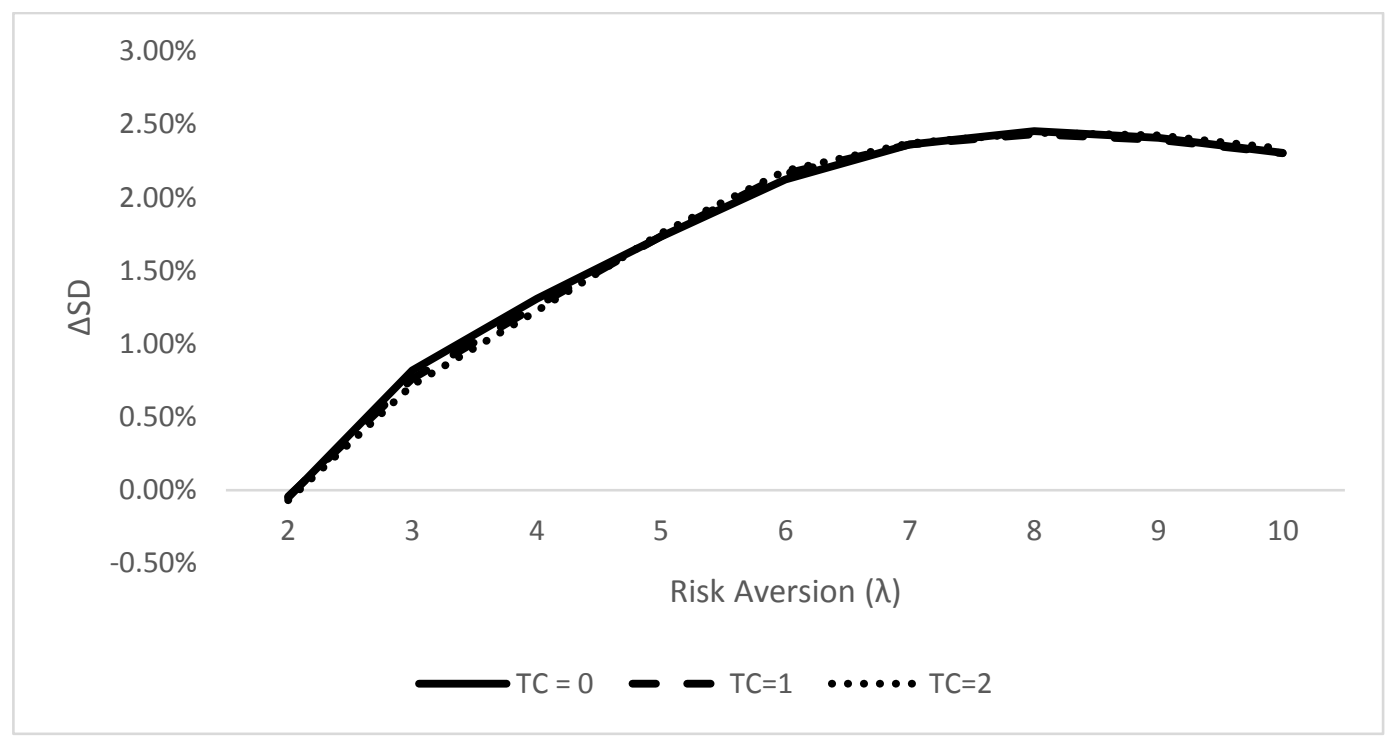

Figure 3: Two Less One Regime Standard Deviations

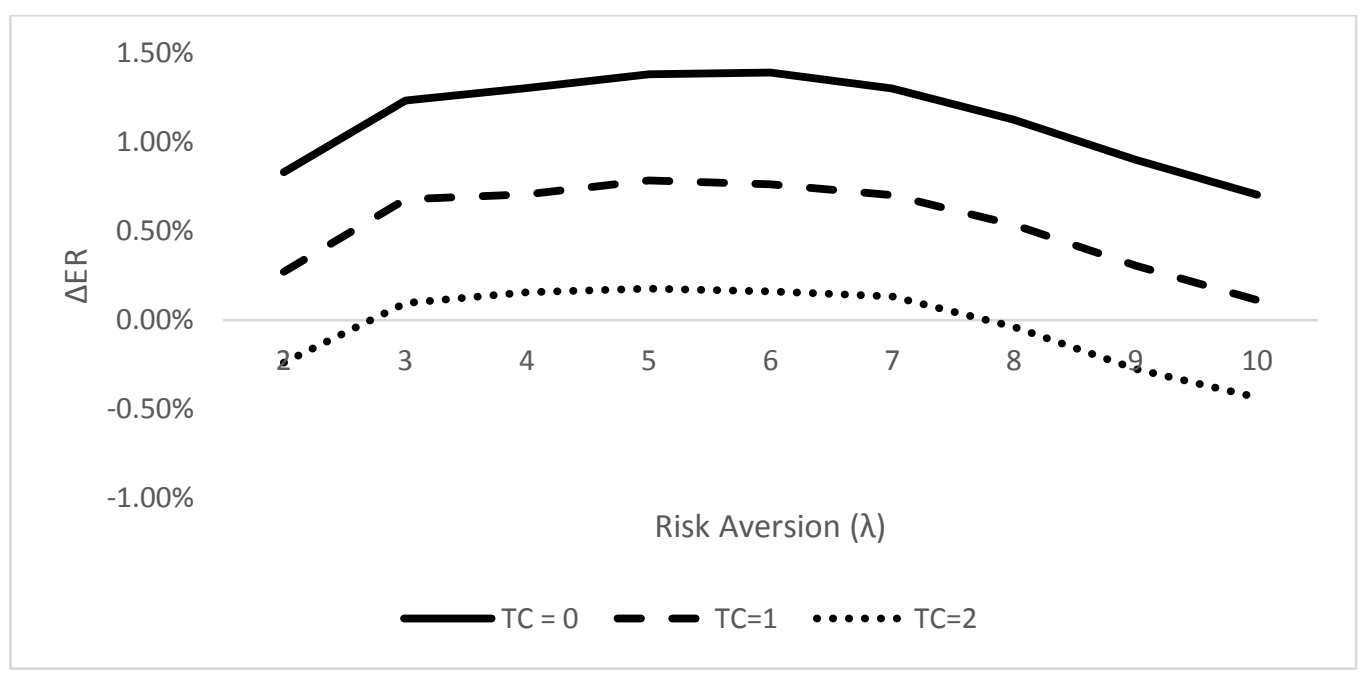

Figure 4: Two Less One Regime Expected Returns 


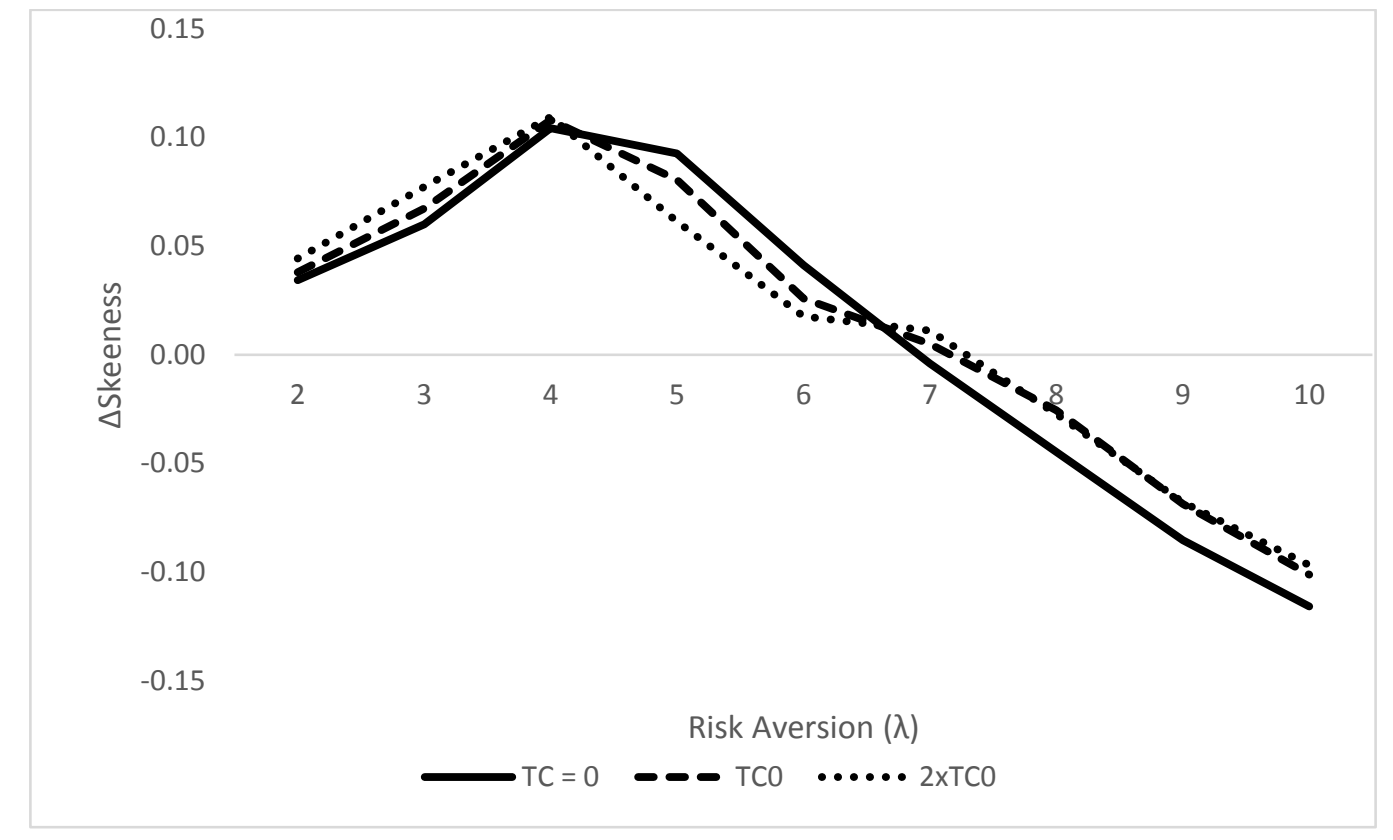

Figure 5: Two Less One Regimes Skewness

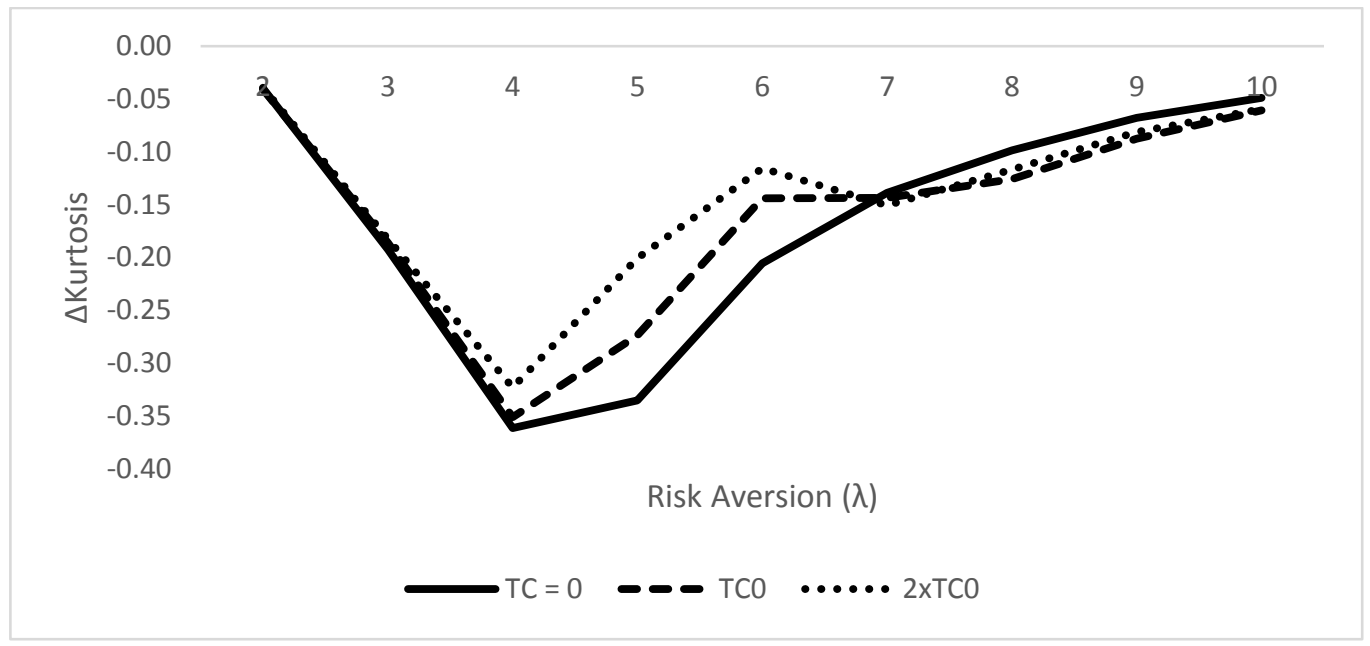

Figure 6: Two Less One Regimes Kurtosis

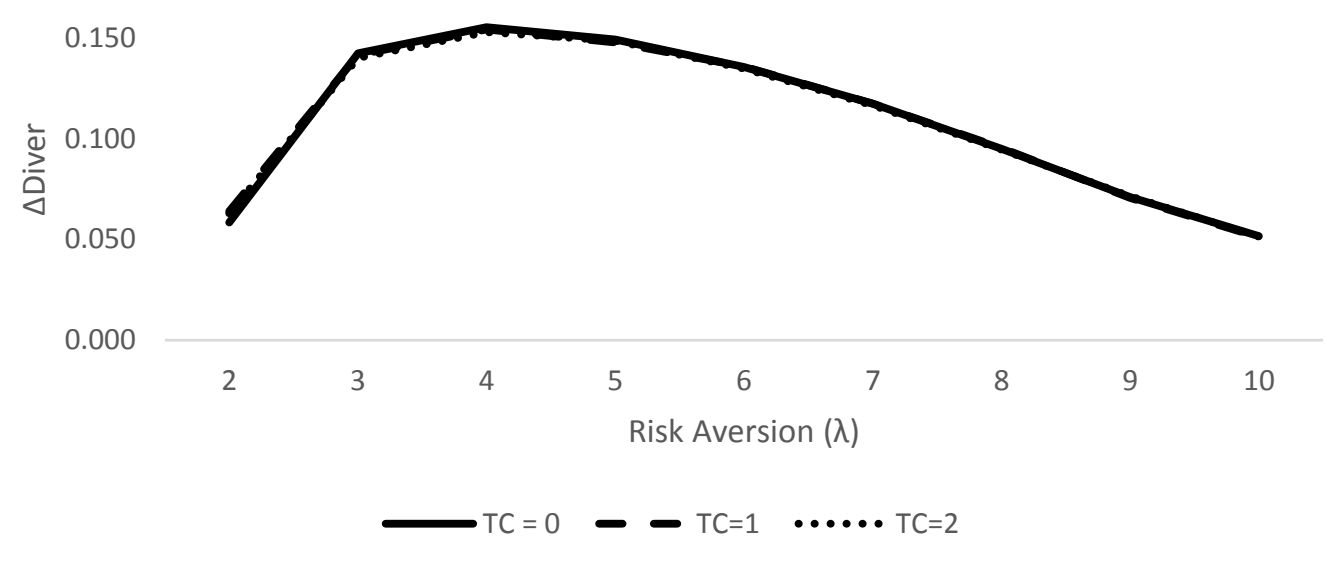

Figure 7: Two Less One Regime Diversification 


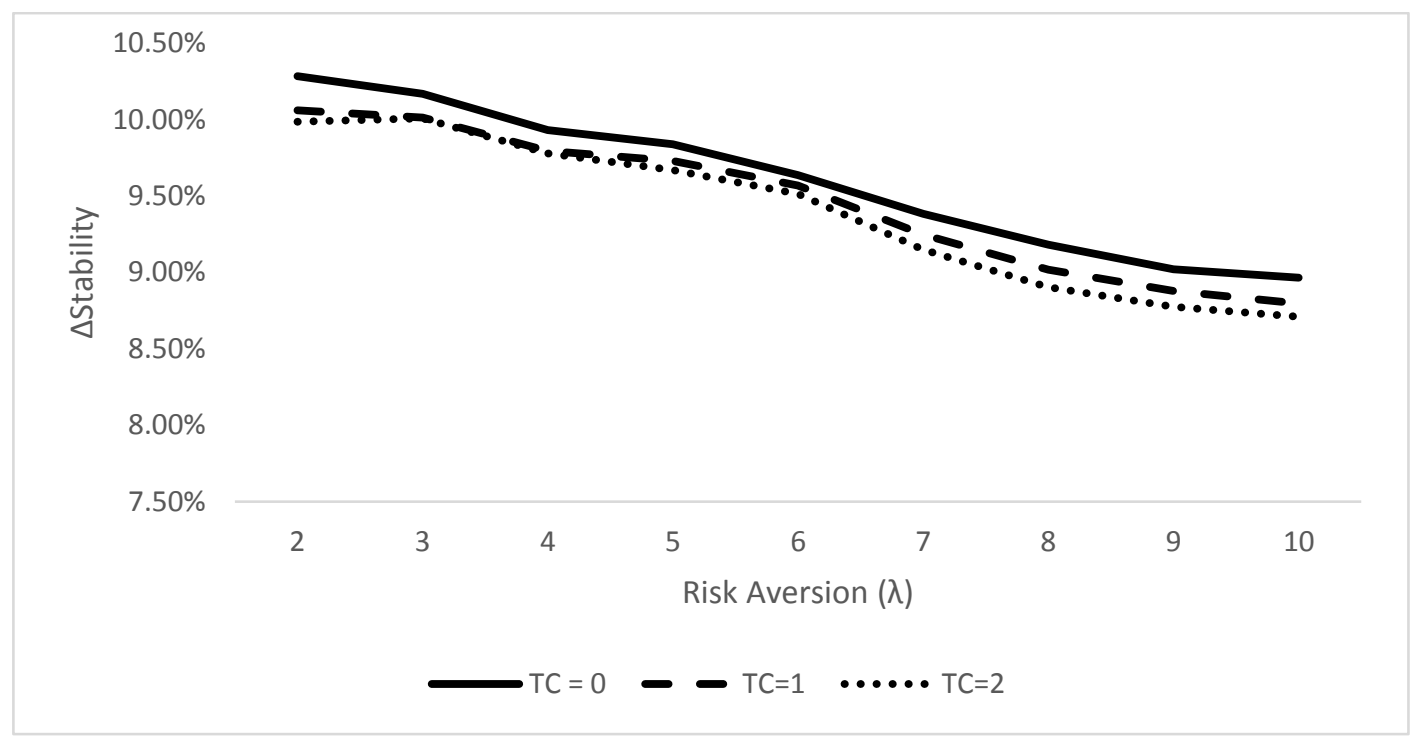

Figure 8: Two Less One Regime Stability 